\title{
Marantaceae endémicas del Perú
}

Blanca León ${ }^{1,2}$

${ }^{1}$ Museo de Historia Natural Av. Arenales 1256, Aptdo. 14-0434, Lima 14, Perú

2 Plant Resources Center, University of Texas at Austin, Austin TX 78712 EE.UU.

blanca.leon@mail.utexas.edu

\section{Resumen}

La familia Marantaceae es reconocida en el Perú por presentar diez géneros y 93 especies (Brako \& Zarucchi, 1993; Ulloa Ulloa et al., 2004), todas ellas hierbas. En este trabajo reconocemos ocho endemismos en dos géneros. Se asignó las categorías de amenaza de la UICN a dos especies. Los taxones endémicos se encuentran principalmente en los bosques de la región del Bosque Húmedo Amazónico, entre los 100 y 700 m de altitud. Aparentemente, los taxones endémicos no están representados en algúnárea natural protegida.

Palabras claves: Marantaceae, Perú, endemismo, plantas endémicas.

\section{Abstract}

The Marantaceae are represented in Peru by 10 genera and 93 species of herbaceous plants (Brako \& Zarucchi, 1993; Ulloa Ulloa et al., 2004). Here we recognize eight endemic species in two genera. We assigned IUCN threat categories to two species. Endemic taxa are mainly found in forests of the Humid Amazonian Forest region, between 100 and $700 \mathrm{~m}$ elevation. No endemic Marantaceae have yet been recorded from a Peruvian protected area.

Keywords: Marantaceae, Peru, endemism, endemic plants.

\section{Calathea jocosa J.F. Macbr.}

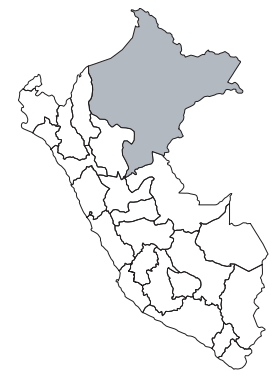

Publicación: Field Mus. Nat. Hist., Bot. Ser. 11(2): 53. 1931.

Colección tipo: L. Williams 3968

Herbarios: F.

Nombre común: Desconocido.

Registro departamental: LO.

Regiones Ecológicas: BHA; altitud desconocida.

SINANPE: Sin registro.

Herbarios peruanos: Ninguno.

Observaciones: Hierba conocida, al parecer, sólo de la colección tipo, una planta recolectada en 1929, de la cuenca del Huallaga. No ha sido posible evaluarla, ni asignarle una categoría.

\section{Calathea longipetiolata H. Kenn.}

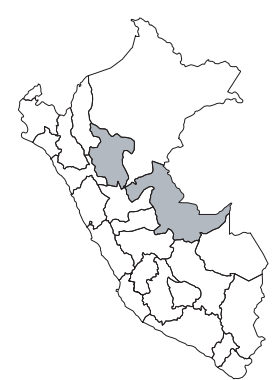

Publicación: Canad. J. Bot. 61: 1432. 1983. Colección tipo: T.C. Plowman 6000 Herbarios: F.

Nombre común: Desconocido.

Registro departamental: SM, UC. Regiones Ecológicas: BMHP, BHA; 400-700 m.

SINANPE: Sin registro.

Herbarios peruanos: USM?

Observaciones: Este taxón fue considerado por Brako \& Zarucchi (1993) como un endemismo; sin embargo, no ha sido posible evaluarlo, ni asignarle una categoría.

\section{Calathea pseudoveitchiana H. Kenn.}

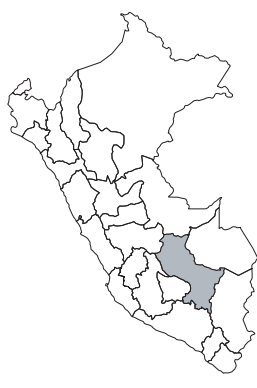

Publicación: Canad. J. Bot. 61: 1429. 1983. Colección tipo: T. Plowman \& W. Davis 5003a ex H. Kennedy 4104 Herbarios: CAN, HLA, K, US.

Nombre común: Desconocido.

Registro departamental: CU.

Regiones Ecológicas: Sin datos; altitud desconocida.

SINANPE: Sin registro.

Herbarios peruanos: Ninguno.

Observaciones: Hierba terrestre descrita de una planta en cultivo, procedente originalmente de Cusco. No ha sido posible evaluarla, ni asignarle una categoría.

\section{Calathea schunkei H. Kenn.}

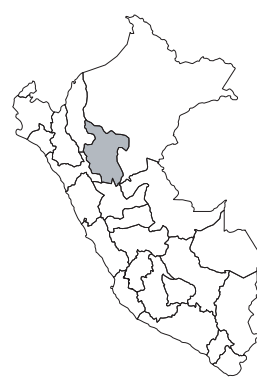

EN, B1a

Publicación: Brittonia 34: 18. 1982.

Colección tipo: $\mathrm{H}$. Kennedy \& T. Plowman 3663

Herbarios:

Nombre común: Desconocido.

Registro departamental: SM.

Regiones Ecológicas: BHA; $400 \mathrm{~m}$.

SINANPE: Sin registro.

Herbarios peruanos: USM (1).

Observaciones: Hierba terrestre descrita de una planta en cultivo, proveniente del río Canuto, un afluente del Huallaga. Otras tres colecciones de herbario confirman la presencia de esta especie en la cuenca del Huallaga. 


\section{Calathea ulotricha J.F. Macbr.}

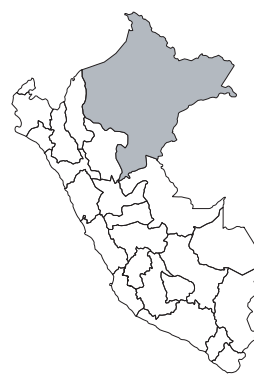

Publicación: Field Mus. Nat. Hist., Bot. Ser. 11(2): 52-53. 1931.

Colección tipo: L. Williams 4921

Herbarios: F, US.

Nombre común: Desconocido.

Registro departamental: LO.

Regiones Ecológicas: BHA; 155-210 m.

SINANPE: Sin registro.

Herbarios peruanos: Ninguno.

Observaciones: Hierba conocida aparentemente sólo de la colección tipo, una planta recolectada a finales de la década de 1920. No ha sido posible evaluarla, ni asignarle una categoría.

\section{Ischnosiphon caudatus L. Andersson}

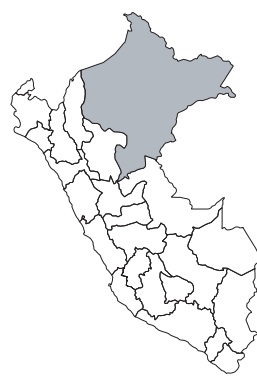

Publicación: Opera Bot. 43: 87-88, f. 3D-E, 40, 41A-B. 1977.

Colección tipo: T. Croat 19987

Herbarios: MO.

Nombre común: Desconocido.

Registro departamental: LO.

Regiones Ecológicas: BHA; altitud desconocida.

SINANPE: Sin registro.

Herbarios peruanos: AMAZ (1).

Observaciones: Este taxón fue considerado por Brako \& Zarucchi (1993) como un endemismo; sin embargo, no ha sido posible evaluarlo, ni asignarle una categoría.

\section{Ischnosiphon fusiformis L. Andersson}

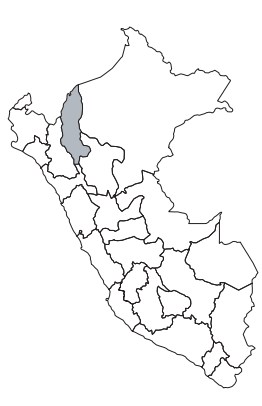

\section{VU, B1a}

Publicación: Nordic J. Bot. 4(1): 31—32, f. 2, 3C. 1984.

Colección tipo: P.J. Barbour 4430

Herbarios: GB, MO; USM!.

Nombre común: Desconocido.

Registro departamental: AM.

Regiones Ecológicas: BMHP, BHA; 200-650 m.

SINANPE: Sin registro.

Herbarios peruanos: HUT (1), USM (isotipo).

Observaciones: Esta especie se conoce de siete localidades, ubicadas en el nororiente del país. Las poblaciones, naturalmente aisladas, están ubicadas en las cuencas de los ríos Chiriaco, Imaza y Mayo. Esta especie fue listada por Jørgensen \& León Yánez (1999) como de probable presencia en Ecuador.

\section{Ischnosiphon parvifolius L. Andersson}

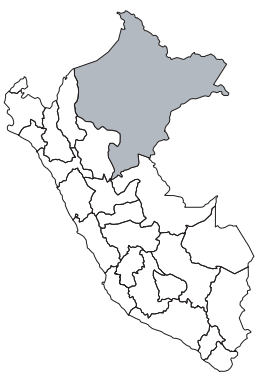

Publicación: Opera Bot. 43: 105-106, f. 4C, 49C, 50. 1977.

Colección tipo: L. Andersson 15

Herbarios: GB.

Nombre común: Bijauillo.

Registro departamental: LO.

Regiones Ecológicas: BHA; 100—140 m. SINANPE: Sin registro.

Herbarios peruanos: AMAZ?, USM?.

Observaciones: Esta especie herbácea se conoce de dos localidades, ubicadas en reservas particulares al noreste de la ciudad de Iquitos (Vásquez, 1997). No ha sido posible evaluarla, ni asignarle una categoría. 